\title{
Experimental Study of Growth and Resorption of Diamond in Kimberlitic Melts at High Pressures and Temperatures
}

\author{
Makoto Arima \\ Geological Institute, Yokohama National University \\ Hodogaya-ku, Yokohama, 240, Japan, and \\ Core Research for Evolutional Science and Technology (CREST), \\ Japan Science and Technology Corporation (JST) \\ e-mail: arima@ed.ynu.ac.jp
}

\section{Introduction}

A genetic link between diamond formation and volatile- and alkali-rich mantle melts or fluids, broadly similar to kimberlite composition has been suggested by studies of inclusions in natural diamonds (Navon et a., 1988). This view is supported by the experimental study by Arima et al. (1993) who demonstrated that diamond crystallized and grew in a volatile-rich silicate melt of kimberlite composition in high-pressure and high-temperature experiments $\left(1800-2200^{\circ} \mathrm{C}\right.$ and $7-7.7$ $\mathrm{GPa}$ ). Complex multistage growth and resorption histories have been noted in some natural diamonds (Taylor et al., 1995). Growth and resorption processes of diamond likely depend on thermal perturbation, mechanism of carbon influx, and redox state in the subcontinental upper mantle. They also depend on the solubility of carbon (or $\mathrm{CO}_{2}$ ) in volatile- and alkali-rich mantle melts or fluids at various depths of the upper mantle.

The morphologies of diamond crystals reflect environmental condition under which they grew and/or dissolved (Sunagawa, 1984). This paper reports detailed growth morphologies of diamonds crystallized from kimberlitic melts in the experiments by Arima et al. (1993), and resorption features of diamond into kimberlitic melts with various carbon contents in the graphite stability field $\left(1300-1500^{\circ} \mathrm{C}\right.$ and $\left.2.5 \mathrm{GPa}\right)$.

\section{Crystallization and growth of diamond at $7-7.7 \mathrm{GPa}$}

Detailed experimental procedures were given in Arima et al. (1993). The kimberlite used in the experiments is an aphanitic kimberlite from Wesselton Mine, South Africa (KIM-1). In the runs at $1800-2200^{\circ} \mathrm{C}$ and $7-7.7 \mathrm{GPa}$, the kimberlite powder was loaded in a graphite capsule with and without a seed diamond (about $1 \mathrm{~mm}$ in diameter), which was emplaced in a Mo capsule. Diamond crystallized and grew from kimberlite melt in all the run. Newly formed diamonds occur in the interface between the kimberlite and graphite capsule, indicating the kimberlite acts as the solventcatalysts. No systematic difference exists between the runs with seed diamond and those without seed diamond at the same P-T condition. No diamond was observed in the "dummy" run in which graphite was encapsulated in a Mo capsule without kimberlite powder. The kimberlite part of the run products consists of a fine-grained crystal aggregate. No glass was observed. Dendritic or acicular morphology of the crystals indicates that they are quench phases crystallized from the kimberlitic melt during quenching at high pressure. Overall, the results indicate that the diamond crystallized from kimberlitic melt and was not formed by solid-state transformation of graphite.

The newly formed diamond crystals, up to $100 \mu \mathrm{m}$ in diameter, are colorless and transparent under optical microscope. They are isolated well faceted octahedron, hopper crystals, or dendritic crystals. The diamonds generally have well developed $\{111\}$ face. In a rare case they have small rugged $\{100\}$ face. Octahedron twinned on $\{111\}$ twin plane is common. In a rare case, cyclic twins are present. The morphology of newly formed diamond in the present experiment indicates that the growth rate of $\{111\}$ is several times lower than those of $\{100\}$, being resemble those of natural diamond but contrast to those of synthetic diamonds grown from metal solvent-catalysts. In addition, in the runs at $2000-2200^{\circ} \mathrm{C}$, a depression at the center of the $\{111\}$ face is locally present, and growth steps indicative of layer-growth are clearly observed.

No apparent change was noted in the original habits of the seed diamonds. However, all the seed diamonds had newly formed triangular patterns on the $\{111\}$ faces. They correspond to growth hillocks that have rounded triangular, truncated triangular, or triangular shape, and have the 
same orientation as the original triangular $\{111\}$ faces of the seed crystal. In a rare case, growth pyramids ( $0.74 \mathrm{~mm}$ high) of triangular morphology clearly show growth steps similar to those observed on natural diamonds (Sunagawa, 1984; van Enckevort, 1992). Rounded hexagonal disklike diamond crystals occur on broken surfaces of the seed diamond (run NK12, $1800^{\circ} \mathrm{C}$ and 7.0 $\mathrm{GPa}$ ). A top face of the disk-like diamond is parallel to $\{111\}$ face of the seed diamond. In addition, shield-like rounded hexagonal growth pattern and "closed loop" of growth steps were noted on $\{111\}$ face of the seed crystal. These features suggest a spiral growth mechanism of the hillocks. It is likely that carbon atoms diffused from the graphite capsule through the kimberlite melt and deposited as diamond on the seed crystal.

\section{Resorption of diamond at $2.5 \mathrm{GPa}$}

Resorption of diamond in kimberlitic silicate melts was investigated at $2.5 \mathrm{GPa}$ and $1300-1500^{\circ} \mathrm{C}$ for 10 to $240 \mathrm{~min}$. using a piston cylinder high pressure apparatus. A natural diamond crystal and a resorption agent (kimberlite powder) were emplaced in a sealed inner Pt capsule ( $2 \mathrm{~mm}$ in diameter). The inner sample capsule was then loaded with the W-I buffer powder in a sealed outer Pt capsule ( $3 \mathrm{~mm}$ in diameter). The natural diamonds used are smooth-faced octahedral crystals $(1 \mathrm{~mm}$ in diameter) with slightly resorbed rounded corner and edge.

To examine the effect of carbon (or $\mathrm{CO}_{2}$ ) concentration in the melt on the diamond resorption, several kimberlite compositions with various carbon (or $\mathrm{CO}_{2}$ ) concentrations were prepared. They were (1) the natural group 1 kimberlite composition from Wesselton Mine, South Africa (4.77 wt.\% $\mathrm{CO}_{2}$ and $6.2 \mathrm{wt} . \% \mathrm{H}_{2} \mathrm{O}$ ), (2) the graphite-doped composition in which graphite powder (20 wt.\%) was added to the Wesselton kimberlite, (3) the carbonate-doped compositions in which $\mathrm{CaCO}_{3}$ was added to the Wesselton kimberlite, and (4) the synthetic kimberlite compositions in which $\mathrm{SiO}_{2}, \mathrm{Al}_{2} \mathrm{O}_{3}, \mathrm{TiO}_{2}, \mathrm{MnO}, \mathrm{MgCO}_{3}, \mathrm{CaCO}_{3}, \mathrm{Na}_{2} \mathrm{CO}_{3}$, and $\mathrm{K}_{2} \mathrm{CO}_{3}$ were mixed with $\mathrm{Fe}$, $\mathrm{FeO}$, or $\mathrm{Fe}_{2} \mathrm{O}_{3}$. No $\mathrm{H}_{2} \mathrm{O}$ was added to these synthetic compositions.

All diamonds in the run-products exhibited a variety of resorption features on $\{111\}$ face including both negatively and positively oriented trigons, hexagonal deep and shallow pits, knoblike asperities, and/or shallow depression with hexagonal morphology. In addition, in most of the run-products, except for those with graphite-doped kimberlite, the diamonds showed preferential resorption of corners and edges of octahedron. In the runs with the natural-kimberlite and carbonatedoped natural kimberlite compositions, extensive resorption occurred and no octahedral faces were preserved after $120 \mathrm{~min}$. In those run, knob-like asperities were noted on corners and edges. Kimberlite portions of the run-products were composed of dendritic quench-crystal aggregates. No graphite was present in all the runs, except for those with graphite-doped kimberlite composition.

All diamonds in the runs-products with natural-kimberlite and carbonate-doped naturalkimberlite compositions showed negatively oriented trigon. A majority of the pits are sharply edged trigons but some shallow pits are in the rounded triangular shape with rounded bottom surface. The trigons include the types of pyramidal-shallow, pyramidal-deep, flat-bottomed-sallow, and flatbottomed-deep, as classified by Frank and Lang (1965). Small trigons $(<1 \mathrm{~mm})$ of both flatbottomed and pyramidal exists within the relatively large trigons. The size of trigon clearly increases with run temperature and run duration. Addition of carbonate to the kimberlite composition suppressed the resorption of diamond.

In the runs with graphite-doped kimberlite composition, the diamonds exhibited no noticeable change in the original habit. No deep-trigon was observed in those runs. The diamonds were covered by graphite and showed shallow depressions with hexagonal morphology on $\{111\}$ face but their corner and edge of octahedron were well preserved. In the runs with synthetickimberlite compositions, both negatively and positively oriented trigons were formed on $\{111\}$ face. In some runs, sharply edged hexagonal deep pits were present on $\{111\}$ face. The run with a melt containing iron of higher oxidation state showed higher degree of resorption features. For example, in the run with $\mathrm{Fe}_{2} \mathrm{O}_{3}$-doped synthetic composition at $1500^{\circ} \mathrm{C}$ and $2.5 \mathrm{GPa}$ for $10 \mathrm{~min}$, corners and edges of octahedron were extensively resorbed and only $50 \%$ of area of $\{111\}$ face was preserved. To the contrary, in the run with FeO-doped synthetic composition at the same run condition, only $25 \%$ of area of $\{111\}$ face was resorbed, and no apparent change was noted in the original habit of the diamond of the run with Fe-doped synthetic composition.

Resorption of diamond is thought to occur within transporting kimberlite magma (Robinson et al., 1989) and in the upper mantle (Taylor et al., 1995). The present experiments clearly 
demonstrate that diamond resorbed in the kimberlite melts in the graphite stability field. The resorption features observed are similar to those reported from natural diamonds (Frank and Lang, 1965; Robinson et al., 1989). The results suggest that the resorption of diamond to kimberlitic melt is a process highly depending on temperature, time, carbon concentration and oxidation state of a resorption agent. Higher temperature, higher oxidation state, and lower $\mathrm{CO}_{2}$ concentration of the kimberlitic melts seem to be favorite conditions for the dissolution of diamond to kimberlite melt. It is likely that carbon was dissolved in the melt as $\mathrm{CO}_{2}$.

\section{Acknowledgments}

The author is grateful to Akaishi, M., Yamaoka, S., Kanda, H. for discussion and technical assistance. He also thanks Nakayama, K., Inoue, M., and Ohkubo, K. for technical assistance. Part of this research was supported by the Grant in Aid for General Scientific Research from the Ministry of Education, Science and Culture (05231216).

\section{References}

Arima, M., Nakayama, K., Akaishi, M., Yamaoka, S., and Kanda, H. Geology, 21, 968-970, 1993.

Frank , F.C., and Lang, A.R., In Physical Properties of Diamond, Berman, ed., Clarendon Press, Oxford, p. 69-115, 1965.

McCallum, M.E., Huntley, O.M., Falk, R.W., and Otter, M.L., In Meyer, H.O.A. and Leonardos, O.H. eds. Diamonds, Characterization, Genesis and Exploration. Procced. 5th Intern. Kimb. Conf. vol. 2., p. 32-50, CPRM, Rio de Janeiro, 1994.

Navon, O., Hutcheon, I.D., Rossman, G.R., and Wasserburg, G.J., Nature, 310, 198-202, 1988.

Otter, M.L., McCallum, M.E., and Gurney, J.J., In Meyer, H.O.A. and Leonardos, O.H. eds. Diamonds, Characterization, Genesis and Exploration. Proceed. 5th Intern. Kimb. Conf. vol. 2., p. 15-31, CPRM, Rio de Janeiro, 1994.

Robinson, D.N., Scott, J.A., Van Niekerk, A., and Anderson, V.G. In Ross, J. et al., ed. Kimberlite and Related Rocks, v. 2. GSA Special Publication, No. 14, Blackwell, Carlton, p. 990-1000, 1989.

Sunagawa, I., In Sunagawa, I., ed., Material science of the Earth's interior, Terra Scientific, Tokyo, p. 303-330, 1984..

Taylor, W.R., Bulanova, G., and Milledge, H.J. Ext. Abst. 6th Intern. Kimb. Conf. 606-610, 1995.

van Enckevort, W.J.P. Journal of Crystal Growth, 119, 177-194, 1992. 